Veer, A. de, Ouden, D.J. den, Francke, A.

Experiences of foreign European nurses in The Netherlands.

Health Policy: 68, 2004, nr. 1, p. 55-61

\begin{tabular}{|c|c|}
\hline Postprint Version & 1.0 \\
\hline Journal website & http://www.sciencedirect.com/science/journal/01688510 \\
\hline Pubmed link & $\begin{array}{l}\text { http://www.ncbi.nlm.nih.gov/entrez/query.fcgi?cmd=Retrieve\&db=pubmed\&dop } \\
\mathrm{t}=\text { Abstract\&list_uids=15033553\&query_hl=4\&itool=pubmed_docsum }\end{array}$ \\
\hline DOI & 10.1016/j.healthpol.2003.08.006 \\
\hline
\end{tabular}

* Corresponding author. Tel.: +31-30-2729764; fax: +31-30-2729729. E-mail address: a.deveer@nivel.nl (A. de Veer).

\title{
Experiences of foreign European nurses in The Netherlands
}

\author{
ANKE DE VEeR*, DiRK-JAN DEN OUdEN, ANNEKE FRANCKE \\ NIVEL, The Netherlands Institute for Health Services Research, P.O. Box 1568, 3500 BN Utrecht, The \\ Netherlands
}

\begin{abstract}
As a result of the shortage of nurses, Dutch health care organizationswant to recruit nurses from outside Europe (e.g. Indonesia, South Africa). The Dutch government, however, is not encouraging this policy and prefers to recruit within the European Union. In order to better support such nurses, it is important to know the problems European nurses encounter in The Netherlands. This study is about the experience of nurses from other European countries in The Netherlands. This paper addresses itself to three principal questions. First, how many nurses qualified in other EU or EU candidate states are starting to work in The Netherlands. Second, why do they come to The Netherlands. And finally what problems do they encounter when working in The Netherlands.

A questionnaire has been send to all registered nurses trained in another EU or EU candidate state. The response has been 987 or $67 \%$.

Thus, far approximately 1500 nurses from other EU/candidate states have come to The Netherlands. Personal reasons, including marriage, are the most important reasons for their coming here. Half of the nurses took one or more courses before starting work in nursing in The Netherlands. These were often Dutch language courses. The nurses had to make a number of adjustments. Major difficulties were unfamiliarity with Dutch laws and the fiscal and social security systems, recognition of their qualifications and application for permits. Some basic issues, such as how to write a letter of application, caused problems. The language and unfamiliarity with the Dutch health care system made it difficult to find a job. When they had gained employment in nursing these problems remained the most serious.

The conclusion is that international employment mobility in nursing is rather low in the case of The Netherlands. If the Dutch government decides to encourage the employment of nurses from abroad, several measures can be taken to make working in The Netherlands more attractive.
\end{abstract}

\section{INTRODUCTION}

This paper focuses on the experiences of foreign European nurses who have been working in The Netherlands or have been searching for a job as a nurse. In The Netherlands and in many other countries, shortages of nursing staff exist [1]. Several hospitals started to recruit personnel from abroad, such as South Africa and the Philippines [2,3]. The Ministry of Health, the Ministry of social affairs and the Dutch parliament are critical about this development [4]. They wanted to investigate the possibilities to recruit in other member states of the European Union. One of the elements they wanted to know was the experience of European nurses in The Netherlands. 


\section{OTHER EU-COUNTRIES RECRUITING NURSES}

Citizens of European member states, Norway, Iceland and Liechtenstein may work in any of these states without applying for work and residence permits. In the future, these rules may also apply to nurses from EU/candidate member states [5]. Attracting nurses from abroad is not a new phenomenon for other European countries. For example, Sweden has a policy of employing people from EUcountries and in particular from Germany [6]. Denmark attracts most foreign nurses (85\%) from other Scandinavian countries and EU countries (9\%) [6]. Ireland and the United Kingdom also make it easy for nurses to work there. Nurses who want to work in Ireland can obtain a special employment permit enabling them to work for a period of 2 years. Both Ireland and the United Kingdom also have an agreement with Spain to employ Spanish nurses on contracts of 12-24 months. In the United Kingdom, overseas nurses make up 3\% of the nursing workforce. But in inner London, they form more than $30 \%$ of the workforce. Overseas nurses account for a quarter of new registrations with the UKCC, the Central Council for Nursing, Midwifery and Health Visiting [7]. Most come from non-EU countries such as South Africa, Australia, The Philippines, New Zealand and the West Indies [8]. In France, private clinics also recruit in Spain (as well as the Lebanon). In Germany, the number of foreign nurses is also increasing (from 4.7\% in 1985 to 5.7\% in 1995) [6]. In Germany, an increasing number of nurses come from Eastern Europe. Many of them are without permits and they try to find employment in the private sector because of the growing demand. The authorities are afraid of immigration by unqualified staff and are searching for solutions to regularize this situation by introducing an au-pair option [6].

\section{POLICY OF DUTCH STAKEHOLDERS}

The policy of the Dutch government is not directed at actively recruiting staff from other EU member states. In general, recruitment is considered as being the responsibility of employers and employees [4]. Representatives of employees also do not stimulate recruitment in other countries, whereas employers primarily want to find staff. In 1998, the Dutch government, representatives of employers and of employees made appointments to regulate the recruitment of personnel from abroad [4]. Recruitment within The Netherlands is preferred, followed by recruiting personnel from other EUcountries. Attracting nurses from non EU-countries is only allowed if these previous actions are unsuccessful and a surplus of personnel in that country exists [4].

More recently the Dutch Association of Nurses and Careworkers emphasized some preconditions. First, they state that adequate training in the homeland is essential and the agent, who acts as a mediator, is qualified to recruit. Furthermore, they point out that Dutch health care organizations should provide sufficient support to the nurse and that at the end both countries benefit from the arrangement [9]. The International Council of Nurses (ICN) has issued a Position Statement that condemns the recruitment of nurses to countries where governments have failed to implement good human resource planning and to seriously address problems that cause nurses to leave the profession. The ICN pleads for so-called 'ethical recruitment' of nurses [10].

\section{RECOGNITION OF PROFESSIONAL NURSING QUALIFICATIONS}

There are several directives that regulate the criteria for professional recognition within the European Union. In 1977, a directive (77/452/EEC) was issued for nurses in general care to facilitate reciprocal recognition. This directive describes training specifications for nurses to qualify as a general care nurse. Training programmes have not yet been harmonized between the member states. Accordingly, only qualifications on the official list are eligible for mandatory and automatic recognition. Each country has its own register and recognition in one country will not lead automatically to recognition in another member state. A special authority assesses qualifications not listed in the official register and assesses certificates and professional experience.

Since 1997, all student nurses in The Netherlands receive general care training. This is not always the case with nurses who receive their training before 1997 and those educated abroad. Nurses with specialist training who first acquired one of the qualifications listed in the nursing directive receive automatic recognition. In the case of nurses with specialist training who did not first acquire one of these qualifications, the host member state first examines their qualifications and compares them with its own training requirements. 


\section{RESEARCH QUESTIONS}

The aim of this study is to answer the following questions:

1. How many nurses, qualified in other European countries, migrated to The Netherlands?

2. Why do they migrate to The Netherlands?

3. How do they prepare for work in The Netherlands? What problems do they encounter when looking for a job? How do they assess their experience of working in The Netherlands?

\section{METHODS}

The BIG register contains the addresses of all registered nurses (RN) in The Netherlands. The country in which the person has received her nursing diploma is not being registered. Therefore, a structured questionnaire was sent to all 2654 nurses in this register in November 2001 with a EU/candidate nationality other than Dutch. The response rate was $67 \%$ or 1768 . Of this group, 987 nurses indicated that they had received their training in a EU/candidate country other than The Netherlands. The other respondents were trained as a nurse in The Netherlands or in a non (candidate) EU country. So 987 nurses completed the questionnaire.

The questions covered reasons for seeking employment in The Netherlands, experience in looking for a job and experience of working in The Netherlands.

Most respondents came from Belgium (46.7\%), Germany (22.7\%) or the United Kingdom (12.8\%) (Table 1). Only a small number of the respondents came from candidate member states, most frequently from Poland (2.1\%). Most respondents were female (87\%) and between 30 and 50 years of age (75\%). Most registered nurses $(91 \%)$ had actually worked or were still working in nursing in The Netherlands.

\section{[ TABLE 1 ]}

A significant number of these nurses (49\%) had at least 10 years of working experience in The Netherlands. Most of them had worked in general hospitals (64\%).

\section{MIGRATION OF STAFF QUALIFIED ELSEWHERE IN EUROPE}

The flow of nursing staff to The Netherlands is small and has been diminishing since 1996 (Table 2). In 2000, only 139 nurses from member states (and Norway, Liechtenstein, and Iceland) were registered as general care nurses. Compared with the overall intake of registered nurses at about 6000 per year [12], this is approximately $2.3 \%$. The intake of nurses from candidate member states in the official register was even smaller: 20 in 2000. At the end of 2001, only 83 nurses trained in a candidate member state were registered as nurses in The Netherlands. The acquisition of a work permit is a problem for this group. In 2001, a total of 116 work permits were provided for nursing and caring staff. Most of these permits (109) were issued to nurses from Indonesia, the Philippines, South Africa and Suriname. Consequently, the number of work permits issued for health care staff from candidate member states was 7 or fewer.

\section{[ TABLE 2 ]}

On the basis of the data, we estimated that there are about 1000 nurses trained elsewhere in Europe and currently working in nursing in The Netherlands [13]. In comparison with the total number of nurses employed in The Netherlands (about 195,000 in 2000 [12]), this makes up about 0.5\% of the total nursing population.

\section{REASONS FOR MIGRATING TO THE NETHERLANDS}

Personal circumstances, such as marriage and a spouse's employment, are the main reasons for coming to The Netherlands (Table 3). Nurses trained in France rate this reason most often as important (96\%). For those from Belgium, personal circumstances are of less importance (42\%). This is mainly due to the fact that the majority of the Belgian nurses (58\%) were working in The Netherlands while still living in Belgium (cross border employment). This does not account for 
German nurses, who also come from a neighbouring country. Cross border employment from Germany is much less common: only 8\% lived in Germany and worked in The Netherlands. German nurses, like those from other countries, generally work in The Netherlands by reason of their personal circumstances.

One-third (32\%) of the nurses also like the working environment in The Netherlands. This is most often reported by Polish and Belgian nurses as an important reason (43 and 42\%, respectively).

The challenge of working abroad and improving professional skills and knowledge were important reasons for nursing abroad with one fifth of the respondents. These reasons were particularly important for those who had recently come to The Netherlands. Nurses from Austria, for example, rated these two reasons most often as important (39 and 44\%, respectively) in comparison with their colleagues from other countries. The secondary conditions of employment were rated by $33 \%$ of the Polish nurses as an important motive.

\section{EXPERIENCE OF NURSES IN THE NETHERLANDS}

Half of the nurses (52\%) followed one or more courses before starting work in nursing in The Netherlands. These were often Dutch language courses. Almost all Belgian nurses came from Flanders and spoke Dutch; so language was no problem for them. One-third (32\%) of the non-Belgian respondents had already learned some Dutch before moving to The Netherlands. Only a small number prepared for work in The Netherlands by taking professional courses. Those most often mentioned were courses on professional knowledge ( $6 \%$ of the respondents) and courses on professional skills (4\%).

The questionnaire dealt with 24 problem areas and the respondents were asked to indicate whether each item was of major, minor or of no importance to them. Table 4 shows 19 items mentioned by at least $10 \%$ of the respondents as being of major importance. The first problem was to become acquainted with the Dutch laws and procedures. One-third experienced problems with Dutch taxes and the social security system. The acceptance of the certificates and professional experience for the required registration as a general care nurse was a problem for about one in every seven. One-fifth of those who would only be accepted as general nurses after a period of working with a supervisor, had difficulties in finding a supervisor. One-fifth did not know where to get the information they required. Another problem when looking for a job is how to write a letter of application, among other things. The Dutch language was most frequently mentioned as a major problem by the non-Belgian respondents. Unfamiliarity with the Dutch health care system also caused problems in finding a job. Nurses who were looking for a job, but did not succeed in getting one, mentioned this difficulty most frequently as an important barrier.

When these important barriers are analyzed for each country, we may be able to determine which group of nurses tended to have the most problems. In Table 4, countries were listed when at least 30\% of the population rated the barrier as important. Nurses from Germany did not seem to have many of problems. The same was true for nurses trained in Belgium. The most important obstacle for these nurses was unfamiliarity with laws and regulations in The Netherlands. Nurses from Spain, Ireland, Great Britain, Denmark and Poland indicated problems on all language-related areas. This, in contrast to nurses from Austria and Finland who did not often have language difficulties, but reported more problems with the health care system and culture-related issues. Of these two countries, it seems that Austrian nurses encountered the most difficulties. Polish and Spanish nurses, in addition to language problems, tended to have more problems with the application procedures, and Spanish nurses also indicated a lack of the required knowledge of the Dutch health care system.

Nurses from Spain and Poland also indicated problems as regards the independence required in The Netherlands and as regards technical procedures (there were not listed in table as less than $10 \%$ of the total population rated these problems as important obstacles).

Language barriers did not differ between those who succeeded in finding a job and those who did not. Most respondents (less than 90\%) did not experience problems regarding their medical-technical knowledge and skills. Once employed in nursing, the Dutch language and the unfamiliarity with the Dutch health care system, remained the main problems (not in Table).

About $70 \%$ of the nurses felt that there was a high level of compatibility between the knowledge and skills they had and the knowledge and skills required. Those who did not have this sense of 
compatibility often thought that they knew, and could do, more than was required. These percentages do not, however, differ from the percentages in the Dutch nursing population [12]. One-third of the nurses would have liked to receive more support from their Dutch employers.

\section{CONCLUSION}

Attempts to make labour markets more fluid within the EU has not resulted in more nurses coming to The Netherlands. The influx of European nurses to The Netherlands has been rather low and even shows a fall from 310 nurses registered as trained in other EU countries in 1996 to 139 in 2000. It is difficult to attract nurses from abroad as most EU-countries suffer from shortages [13], making it a global problem. Recently, the Dutch labour market for nurses is expected to change because of an economic decline. This might be the reason that the attention from Dutch policy-makers and the media about this topic seems to subside. Nevertheless, there will still be shortages of nursing staff in the future [1].

Most of the European nurses who participated in our survey entered The Netherlands because they moved with their partners or family or because of other personal circumstances. They encountered many barriers while looking for a job. The Dutch language in particular was a problem. This conclusion is also the opinion of employers [13]. Employers also stress that it would be more successful if the candidate knows the Dutch language. Furthermore, employers stress that it is important that the candidate's culture resembles the Dutch culture, that the introduction into the organization is well structured and guided, the team has a positive attitude towards the new employee and the new employee is willing to adopt the Dutch approach to caring and nursing. These data correspond with the experience of the nurses reported in this article.

New nurses should not only learn the Dutch language, but also undergo a period of induction, which covers the Dutch health care system and its culture as well as information about social services, tax schemes and how to find suitable accommodation. At this point, the government is not entirely passive. To resolve the lack of information, the Dutch Ministry of Health started a helpdesk for those qualified abroad and for Dutch health care employers in 2002 to act as a guide to the Dutch system.

The medical-technical knowledge and skills of the nurses educated elsewhere were more than adequate and caused no significant problems. To get officially registered was yet a major problem. It is difficult to know the skills and experiences acquired in another country and compare it with the Dutch situation. There should be a European nursing labour market, with comparable levels of qualification for nurses and comparable information about supply and demand of nurses in each country. The information about EU labour markets is scarce and needs further development and harmonization. Health care professionals transferring their practices from country A to country B will have to be subjected to professional rules and mechanisms of quality assurance in both countries, preferably using a similar procedure [14]. In the short term, a list of similar qualifications from each country would be helpful.

The number of newly registered nurses from EU candidate countries was even lower than those from EU countries: 20 in 2000. Nurses from these EU-candidate countries who would like to work in The Netherlands need work and residence permits, which are very difficult to acquire. Another cause of the low number of nurses from EU candidate countries may be that their nursing training is not judged sufficient for general care nursing qualifications. The Dutch government recently took the first steps to make it easier for them to work in The Netherlands. In 2002, a group of about 30 Polish nurses got permission to work temporarily in The Netherlands as auxiliary nurses. A final remark concerns the necessity of recruitment abroad. The potential success of recruitment from abroad is acknowledged, but the broader economic perspective also needs to be assessed. The costs of these benefits should be considered and compared with the ways that recruitment can be enhanced. For example, with the costs of attracting other groups already in The Netherlands, such as asylum seekers or nurses who have stopped working in nursing, or as the trades unions stress, the quality as well as the payment of nurses could be improved.

\section{ACKNOWLEDGEMENTS}

The authors acknowledge Institute for Labour Studies (OSA) for commissioning and financing. 


\section{TABLES}

Table 1

Characteristics of the responders $(n=987)$

\begin{tabular}{|c|c|c|}
\hline & Number & $(\%)$ \\
\hline \multicolumn{3}{|l|}{ Country } \\
\hline Belgium & 461 & 46.7 \\
\hline Germany & 224 & 22.7 \\
\hline United Kingdom & 126 & 12.8 \\
\hline France & 28 & 2.8 \\
\hline Denmark & 25 & 2.5 \\
\hline Austria & 21 & 2.1 \\
\hline Poland & 21 & 2.1 \\
\hline Spain & 17 & 1.7 \\
\hline Finland & 16 & 1.6 \\
\hline Ireland & 15 & 1.5 \\
\hline Italy & 12 & 1.2 \\
\hline Sweden & 9 & 0.9 \\
\hline Portugal & 5 & 0.5 \\
\hline Czech Republic & 3 & 0.3 \\
\hline Romania & 2 & 0.2 \\
\hline Turkey & 1 & 0.1 \\
\hline Slovenia & 1 & 0.1 \\
\hline \multicolumn{3}{|l|}{ Age (years) } \\
\hline$<30$ & 121 & 12 \\
\hline $30-39$ & 409 & 41 \\
\hline $40-49$ & 338 & 34 \\
\hline$\geq 50$ & 118 & 12 \\
\hline Unknown & 1 & 0.1 \\
\hline \multicolumn{3}{|c|}{ Current employment status in The Netherlands } \\
\hline Works as a nurse & 669 & 68 \\
\hline $\begin{array}{l}\text { Has been working as a } \\
\text { nurse (not anymore) }\end{array}$ & 228 & 23 \\
\hline $\begin{array}{l}\text { Looked for a job as a nurse } \\
\text { but did not succeed }\end{array}$ & 42 & 4 \\
\hline $\begin{array}{l}\text { Has never searched for a } \\
\text { job as a nurse }\end{array}$ & 48 & 5 \\
\hline
\end{tabular}

Table

Inflow of nurses to The Netherlands from other EU member states, Norway, Liechtenstein and Iceland since 1996 [11]

\begin{tabular}{ll}
\hline Year & Nurses \\
\hline 1996 & 310 \\
1997 & 209 \\
1998 & 185 \\
1999 & 152 \\
2000 & 139 \\
\hline
\end{tabular}

Table 3

Main reasons for going to The Netherlands $(n=939)$

\begin{tabular}{lll}
\hline Reason & Nurses (\%) & Especially in \\
\hline $\begin{aligned} \text { Personal circumstances } \\
\text { (e.g., moved with partner) }\end{aligned}$ & 60 & Fr, Sp, De, Ir, \\
& & Ge, GB, Au, \\
& Fi, Po, Be
\end{tabular}

Good working environment $32 \quad \mathrm{Po}, \mathrm{Be}$

Challenge of work abroad ${ }^{\mathrm{b}} \quad 26 \quad \mathrm{Au}, \mathrm{Fi}, \mathrm{Ir}, \mathrm{Ge}$,

GB, Po

Good additional training

possibilities

Good secondary conditions $\quad 12 \quad$ Po

of employment

Good career-opportunities $\quad 12$

Good salary ${ }^{\mathrm{b}}$

a More often mentioned as an important reason by nurses of the following countries-Au: Austria; Be: Belgium; De: Denmark; Fi: Finland; Fr: France; Ge: Germany: GB: Great Brittain: Ir: Ireland; Po: Poland; Sp: Spain. Reasons are listed if at least $30 \%$ of the population rated the specific reason as important. Countries are listed in a descending order based on the percentage of the population that rated the specific reason as important.

$\mathrm{b}$ More often mentioned as an important reason by nurses who recently came to The Netherlands (ANOVA, $P<0.05$ ).

\section{REFERENCES}

[1] van der Windt W, Calsbeek $\mathrm{H}$, Talma $\mathrm{H}$, Hingstman L. Feiten over verpleegkundige en verzorgende beroepen in Nederland 2002. Utrecht/Maarssen: LCVV/Elsevier Gezondheidszorg; 2002.

[2] Visser E de. Buitenlandse Hulp. De Volkskrant; 22 September 2001.

[3] Bals K. Uitzendbureau schrikt terug van jungle. Aaneen; 4 November 2000.

[4] Tjadens F, Roerink H. Arbeidsmigratie door verpleegkundigen naar Nederland. Utrecht: NIZW; 2002.

[5] SER. Arbeidsmobiliteit in de EU. Den Haag: SER; 2001.

[6] Schneider M, Hofmann U, Jumel S, Köse A. Beschäftigungsunterschiede in ausgewählten Gesundheitssystemen der EU. Augsburg: Basys; 2002.

[7] Buchan J. Nurse recruitment. Abroad minded. Health Services Journal 2000;110(5686):20-1.

[8] Buchan J. Recruitment. Happy landing. Health Services Journal 2000;110(5719):24-7.

[9] AVVV. Standpuntbepaling AVVV ten aanzien van actieve werving verpleegkundigen en verzorgenden uit het buitenland. Utrecht: AVVV; 2002.

[10] ICN. Ethical recruitment of nurses. Framework announced by ICN. Geneva: ICN; 2002.

[11] Hingstman L, Kenens R, van der Windt W, Talma HF, Meihuizen HE, Josten EJC. Rapportage arbeidsmarkt Zorg en Welzijn 2002. Bijlagen. Tilburg: OSA; 2002.

[12] Calsbeek $\mathrm{H}$, Hingstman L, Talma $\mathrm{H}$, van der Windt W. Feiten over verpleegkundige en verzorgende beroepen in Nederland 2001. Utrecht/Maarssen: LCVV/Elsevier Gezondheidszorg; 2001.

[13] De Veer AJE, Den Ouden DJ, Francke AL. Grenzen Geslecht? Ervaringen van en met zorgpersoneel uit EU-(kandidaat) lidstaten. Tilburg: OSA; 2002.

[14] Legemaate J. Integrating health law and health policy: a European perspective. Health Policy 2002;60:101-10. 